\title{
Using functional genomics to explore the effects of ocean acidification on calcifying marine organisms
}

\author{
Gretchen E. Hofmann ${ }^{1, *}$, Michael J. O'Donnell ${ }^{1,2}$, Anne E. Todgham ${ }^{1}$ \\ ${ }^{1}$ Department of Ecology, Evolution, and Marine Biology, University of California Santa Barbara, Santa Barbara, \\ California 93106-9610, USA \\ ${ }^{2}$ Present address: Friday Harbor Laboratories, University of Washington, 620 University Road, Friday Harbor, \\ Washington 98250, USA
}

\begin{abstract}
As the research community attempts to forecast the effects of ocean acidification on marine ecosystems, a critical element is a clear understanding of the effects of ocean acidification on an individual organism's physiology. This article explores how the use of genomics-based tools that measure gene expression - DNA microarrays and quantitative PCR — can assist in this effort and reveal aspects of how calcifying marine organisms will respond to ocean acidification. More specifically, what stands to be gained from this approach is an understanding of the direct effects of ocean acidification and whether organisms have sufficient physiological plasticity to adapt to the altered $\mathrm{CO}_{2}$ conditions. We provide a brief overview of biomineralization processes in corals and sea urchin larvae, and then link these pathways to ways in which gene expression analysis can reveal physiological responses and mechanisms, and further, can define new testable hypotheses. In addition, we review the resources available and strategies that might be taken for each of 2 study organisms, stony corals and sea urchins. Finally, we suggest strategies for gene expression profiling in organisms that differ in availability of genomic resources.
\end{abstract}

KEY WORDS: Ocean acidification · Biomineralization · Microarrays - Calcification · Coral · Gene expression · Genomics · Sea urchin

\section{INTRODUCTION}

As the research community explores the effects of ocean acidification on marine ecosystems (Royal Society 2005, Kleypas et al. 2006), a key link to forecasting the effects of this altered seawater chemistry is understanding the response at the organismal level. A potentially productive path for the ocean acidification research community is to leverage genomics tools (Box 1) to understand the mechanisms that might be driving altered skeleton formation in marine calcifying organisms, and in addition, to reveal whether potential compensation in the key pathways for biomineralization and other processes is possible.

Genomics approaches have been solidly integrated into the general field of ecology. Notably, transcriptomics - the measurement of all mRNAs in a biological sample, usually performed with a microarray-has recently emerged in marine ecology (Hofmann et al. 2005). Notably, since microarrays have been used to assess the physiological responses of organisms to abiotic environmental conditions (Gracey 2007), they also have the potential to highlight pathways that are changing in response to elevated $\mathrm{CO}_{2}$.

There are many barriers to success in using microarrays or other methods to profile gene expression (e.g. quantitative PCR [qPCR]), but they generally narrow down to whether there is sufficient DNA sequence available for a particular species to support the construction and use of a microarray or the design of genespecific primers for qPCR. Fortunately, there is significant movement in the field as more libraries and platforms are available for ecologically and economically important marine species. Additionally, in the ab- 
Box 1. Quantitative PCR \& microarrays. Several tools exist to quantify the expression of gene transcripts within organisms. Two promising techniques for assessing effects of ocean acidification are described

\begin{abstract}
Quantitative PCR (qPCR). A modification of the standard PCR in which CDNA is quantified after each round of amplification (real-time) as opposed to end-point analysis. qPCR determines the relative starting quantity of messenger RNA (mRNA) in a sample with high resolution and precision and enables the researcher to quantify relative gene expression in a cell or tissue type at a particular time. This technique focuses on a single to few genes at a time and consequently is a more targeted approach to identifying mechanisms or describing a particular physiological pathway. qPCR is also used to verify DNA microarray results for a smaller set of genes. For qPCR, sufficient sequence information is preferred to create gene-specific primers.

Microarrays. The power of the microarray technology is in its scale. This technique allows for the simultaneous quantification of thousands of mRNAs in a given sample and therefore enables the researcher to profile the expression of genes involved in a large number of physiological pathways in a single step. Microarrays consist of glass slides spotted with up to tens of thousands of 'features': short segments of single DNA sequences in high density. Using competitive hybridization of 2 alternatively labeled samples to the feature spots, microarrays measure the relative abundance of thousands of mRNAs in a 'control' vs 'experimental' sample. While
\end{abstract}

microarrays lack the detailed resolution of qPCR and can be technically more challenging to implement, the capacity to profile an organism's genome-wide response to a particular environmental condition makes this tool invaluable to ecological genomics. Below we outline the two primary microarray technologies used for gene expression analysis.

cDNA microarray: For non-model systems with little to no available sequence information, it is possible to construct a library of all potentially expressed mRNA transcripts found within individuals of the target species. These cDNAs can then be spotted as 'features' on a microarray. cDNA microarrays are inexpensive to manufacture, but require considerable time and effort to develop the underlying cDNA library.

Oligonucleotide microarray: Where sufficient sequence information exists, such as for model organisms or those with completely sequenced genomes, it is possible to select sequences from a database and simply order an array of synthesized gene-specific oligonucleotide 'features'. While oligo arrays offer a more sensitive and reproducible microarray technology for genome-wide transcript profiling, they are considerably more expensive than cDNA arrays and may be limited in their capacity for cross-species hybridizations. sence of a sequenced genome, there are strategies that will allow some level of gene expression analysis in almost any organism (see Table 1). In this article we hope to highlight the utility of gene expression profiling and its potential to provide deeper insight into mechanisms of biomineralization in important marine calcifiers. We briefly outline the techniques, suggest candidate calcifying marine organisms that are currently most fruitful for this pursuit, and highlight how gene expression profiling can serve as a powerful tool to examine the response of organisms to ocean acidification regardless of whether a genome database exists or not.

\section{CANDIDATE STUDY ORGANISMS}

Certainly one of the obvious initial questions is: Which marine organisms best support using gene expression profiling to address cellular- and molecular-level mechanisms in ocean acidification scenarios? Another is: Which species are critical to study due to the urgency of the ocean acidification problem? Since these approaches are significantly facilitated by access to DNA sequence information, a ranking of organisms by the depth of genomic and molecular resources is perhaps one of the first steps to consider. As we see it, amongst marine organisms, there are 5 excellent candidates: the purple sea urchin Strongylocentrotus purpuratus, scleractinian corals, oysters, limpets and coccolithophorids. A microarray-based approach has already been used in the study of calcification in coccolithophorids (Quinn et al. 2006). For the calcifying marine invertebrates, genomics resources are available in the form of sequenced and annotated genomes (Sea Urchin Genome Sequencing Consortium 2006) or excellent microarray resources are in place (Forêt et al. 2007, Jenny et al. 2007, Desalvo et al. 2008). Other strategies are available for investigators interested in non-model but ecologically critical species. Specifically, the design of PCR primers is possible given the available sequence data in various databases (Table 1). Additionally, efforts to obtain sequence data for critical species such as pteropods in high latitude seas are underway using pyrosequencing (G. Hofmann \& V. Fabry unpubl. data), and highly feasible given the increasing availability of affordable high-throughput sequencing and its proven utility in the study of ecologically important questions (Vera et al. 2008).

However, for the purpose of this article, we will focus on how to apply functional genomics to the question of the effects of ocean acidification on sea urchins, due to the availability of the data in the sequenced genome, and, secondly, for stony corals given their ecological importance in biomineralization in coral reef ecosystems.

\section{EVIDENCE FOR THE IMPACT OF OCEAN ACIDIFICATION: WHERE TO START}

For our purposes, it would be useful to first identify the cellular mechanisms involved in biomineralization, 
Table 1. Candidate genes in marine calcifying organisms that currently lack a sequenced genome

\begin{tabular}{|c|c|c|c|}
\hline Gene for: & Function & Organism & GenBank accession no. \\
\hline $\begin{array}{l}\text { Nacrein or } \\
\text { nacrein-like proteins }\end{array}$ & $\begin{array}{l}\text { Thought to play a role in the regulation of calcium } \\
\text { carbonate }\left(\mathrm{CaCO}_{3}\right) \text { crystal formation in mollusk shells }\end{array}$ & $\begin{array}{l}\text { Oyster } \\
\text { Scallop } \\
\text { Snail }\end{array}$ & $\begin{array}{l}\text { D83523, AB252484, } \\
\text { AB252480 } \\
\text { AB252482 } \\
\text { AB073680 }\end{array}$ \\
\hline $\begin{array}{l}\text { Chitin synthase } \\
\text { (ArCS-1p) }\end{array}$ & $\begin{array}{l}\text { Involved in chitin deposition in the mollusk } \\
\text { shell during nacre formation }\end{array}$ & Pen shell & DQ081727 \\
\hline Perlustrin & $\begin{array}{l}\text { Believed to play a role in the nucleation and/or } \\
\text { the growth of } \mathrm{CaCO}_{3} \text { crystals }\end{array}$ & Abalone & P82595 \\
\hline Lustrin A or lustrin & $\begin{array}{l}\text { Control the morphology and packing of } \mathrm{CaCO}_{3} \\
\text { crystals by becoming occluded in the mineralized } \\
\text { composite during shell formation }\end{array}$ & Abalone & AF023459, DQ298402 \\
\hline Perlucin & $\begin{array}{l}\text { Believed to play a role in the nucleation and/or } \\
\text { the growth of } \mathrm{CaCO}_{3} \text { crystals }\end{array}$ & Abalone & P82596 \\
\hline Perlinhibin & $\begin{array}{l}\text { Involved in the inhibition of } \mathrm{CaCO}_{3} \text { crystal } \\
\text { growth and dissolution }\end{array}$ & Abalone & P85035 \\
\hline Shell matrix proteins & $\begin{array}{l}\text { Control the morphology and packing of } \mathrm{CaCO}_{3} \\
\text { crystals by becoming occluded in the mineralized } \\
\text { composite during shell formation }\end{array}$ & $\begin{array}{l}\text { Scallop } \\
\text { Mussel }\end{array}$ & $\begin{array}{l}\text { AB073617 } \\
\text { AY364453 }\end{array}$ \\
\hline $\begin{array}{l}\text { Pearlin or } \\
\text { pearlin-like proteins }\end{array}$ & $\begin{array}{l}\text { Control of nucleation of the first layer of oriented } \\
\text { calcite/aragonite in deposition of the abalone } \\
\text { shell and flat pearl }\end{array}$ & $\begin{array}{c}\text { Oyster } \\
\text { Pen shell }\end{array}$ & $\begin{array}{l}\text { AB020779, AB159512, } \\
\text { AB094512 } \\
\text { AF145215 }\end{array}$ \\
\hline
\end{tabular}

an exercise that will highlight the types of genes that could be driving the observed changes in biogenic calcification in our 2 study organisms, sea urchins and stony corals (Fig. 1). Although numerous experimental studies have demonstrated that elevated $\mathrm{CO}_{2}$ has a sub-lethal impact on organismal, developmental and physiological features in marine calcifying organisms (Fabry et al. 2008, Guinotte \& Fabry 2008, Doney et al. 2009), very little is known about the cellular-level mechanisms that alter these processes in response to elevated $\mathrm{CO}_{2}$ conditions. Additionally, since marine calcifiers have different forms of the biomineral calcium carbonate (Lowenstam \& Weiner 1989), we expect the responses to vary by taxon. Thus, a taxonomically broad effort, encompassing a variety of calcifiers, will capture individual responses that can integrate to reveal impacts on ecosystem-level processes.

\section{Sea urchins}

Due to its status as a model organism for development, the purple sea urchin has emerged as the marine invertebrate with the deepest genomic resources. Combined with a developed view of how biomineralization occurs in sea urchin embryos (Wilt 2002), the opportunity to use genomics approaches to explore the expression of genes involved in biomineralization are rich (Livingston et al. 2006). When considering how to begin these studies, we have identified a suite of genes that, if targeted, can reveal considerable detail into how ocean acidification and elevated $\mathrm{CO}_{2}$ will impact biomineralization and skeleton formation in larval and adult sea urchins (A. Todgham \& G. Hofmann unpubl. data). These 3 classes are (1) genes for proteins in the organic matrix, (2) genes for transporters in membranes, and (3) genes coding for carbonic anhydrase, an enzyme that drives $\mathrm{CO}_{2}$ elimination in cells (Fig. 1).

If, in this first-cut analysis, we focus on the effect of $\mathrm{CO}_{2}$ on the process of spicule formation in the sea urchin larvae, we would examine genes that are involved in biomineralization during skeletogenesis. In sea urchins, the spicule is formed by primary mesenchyme cells (PMCs) where the PMCs act as a cytoplasmic sheath around the forming spicule (Fig. 1). Gene expression in the PMCs is thought to be involved in calcium transport where calcium is transported from the external seawater, modified in the PMC cytoplasm, and then moved via exocytosis into the extracellular space around the forming spicule. In addition to genes involved in calcium transport to form calcite, there are proteins that facilitate precipitation of calcium in the spicule and there are also 45 proteins that have been identified in association with the spicule. Although the roles of all these proteins are not known, some of them are well known, e.g. SM30 is embedded in the mineral phase of the spicule and SM30 and SM50 have high expression rates at the growing nascent tips of larval spicules (Wilt 2002). Should sea urchin larvae be able to compensate for the impact of $\mathrm{CO}_{2}$ on biomineral- 


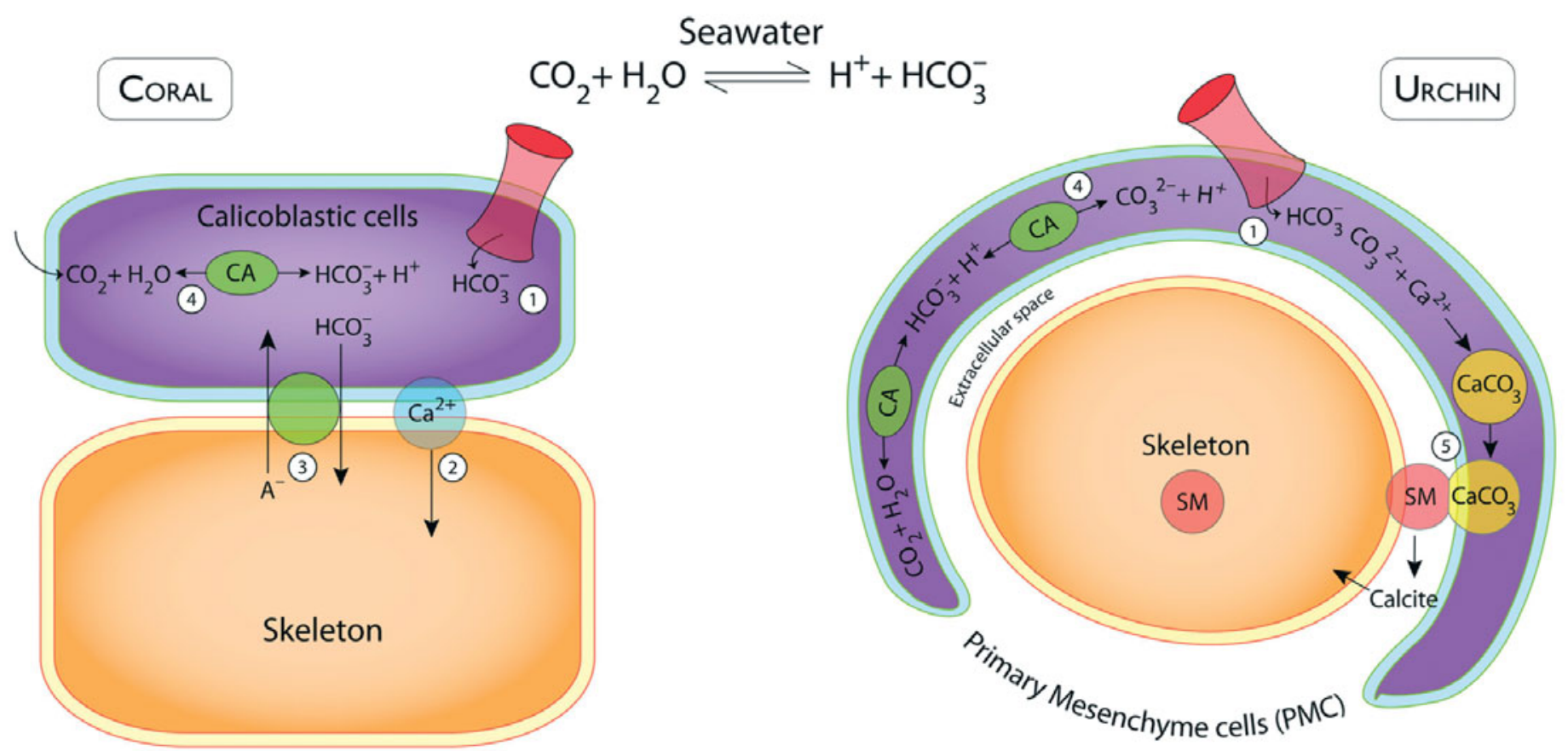

Fig. 1. Cellular pathways involved in calcification and skeleton biogenesis in sea urchins and corals. This schematic shows the cell types that form the skeleton of the coral polyp and the sea urchin larvae. The numbers within indicate general classes of genes that would be likely targets for study, or that may be predicted to exhibit changes in expression patterns, given their role in biomineralization. For corals, the calicoblastic cell forms the skeleton, and in sea urchin larvae, the primary mesenchyme cells (PMCs) form a cytoplasmic syncitium around the growing spicule (skeleton rod in the larvae). The genes encoding the following proteins are part of the general process of biomineralization: 1, various transmembrane transporters for $\mathrm{HCO}_{3}{ }^{-}$and calcium from surrounding seawater; 2 , transmembrane transport of calcium from the cytoplasm of the calicoblastic cell to the extracellular space where the calcium is mineralized at the skeleton; 3 , anion exchangers that transport carbonate to the site of calcification; 4, action of carbonic anhydrase (CA), an enzyme that converts $\mathrm{CO}_{2}$ in the cell; 5 , in sea urchins, certain spicule matrix proteins (SM) are involved in directing biomineralization in the extracellular space between the PMC and the growing skeleton. Sea urchin drawing after Wilt (2002)

ization, one might predict that there would be changes in the expression of these genes. Notably, recent studies have shown sub-lethal effects of $\mathrm{CO}_{2}$ on skeleton formation in sea urchins (Kurihara \& Shirayama 2004), and gene expression studies indicate that expression patterns of spicule matrix proteins change with $\mathrm{CO}_{2}$ levels (A. Todgham \& G. Hofmann unpubl. data).

\section{Corals}

Because a fully sequenced genome is not available for a species of stony coral, the resources are not as advanced as they are for sea urchins. However, there are DNA sequence data available for numerous species (reviewed in Forêt et al. 2007), microarray and qPCR studies are very achievable (de Boer et al. 2007, Schwarz et al. 2008, Mayfield et al. 2009), and this effort could easily be turned to questions of the impact of ocean acidification.

For corals, skeleton formation requires the transport of calcium and dissolved inorganic carbon (DIC) from seawater to the site of calcification at the epithelium of the calicoblastic cells (Fig. 1) of a coral polyp to form aragonite, a calcium carbonate mineral that makes up the skeleton in combination with the organic matrix (reviewed in Allemand et al. 2004). Although our 'gene targeting' approach is less clear-cut due to the complexities of coral skeletogenesis, ocean acidification impacts on biogenic calcification in corals can be examined by looking at active processes that are driven by a protein or a transport mechanism (Fig. 1).

In terms of calcium transport, early work indicated that calcium is delivered to the site of calcification by transcellular transport (reviewed in Gattuso et al. 1999, Cohen \& McConnaughey 2003). Recent research supports these earlier studies and measured intracellular gradients of calcium that suggested the active, transcellular transport of calcium (Marshall et al. 2007). Calcium channels have been found in the calicoblastic epithelium and a goal would be to target the expression of these genes (Zoccola et al. 1999).

For the carbon source, benchmark research first showed that the carbonate in the skeleton can originate from 2 carbon sources, either from metabolic $\mathrm{CO}_{2}$ or from soluble carbonate in external seawater. More recent research has focused on the source of carbon for coral skeleton formation and has pointed towards cel- 
lular processes of interest. For example, the role of carbonic anhydrase has recently been the focus of biochemical research and this enzyme activity is found in tissues and in the organic matrix of an azooxanthellate coral (S. Tambutté et al. 2007). In addition, immunochemical methods have shown that calicoblastic cells are secreting components of the organic matrix $(\mathrm{Pu}-$ verel et al. 2005, 2007) and some of these matrix proteins have been cloned (Fukuda et al. 2003). Taken together, these accumulating experimental observations, and studies further describing the tissue-skeleton interface, argue for an active role of calicoblastic cells in the physiological process that controls calcification of the coral skeleton (E. Tambutté et al. 2007), and that, for example, carbonic anhydrase expression would be a good target of study. Most importantly, if more genes are explored in this endeavor, it will be possible to get a physiological fingerprint of the response of corals to ocean acidification and have a more comprehensive view of calcification. This endeavor is underway as more genomic resources for corals become available, a situation that will lead to clearer understanding of the skeletogenesis in corals in general, and then how this process will respond to ocean acidification at the molecular and cellular level.

\section{GLOBAL PHYSIOLOGICAL RESPONSE TO OCEAN ACIDIFICATION}

It should not be forgotten that a transcriptomics approach also affords the investigator a view of many metabolic processes, not just the activity of those genes involved in biomineralization. In many ways, this 'discovery' aspect of the genomics approach supplies a platform on which future hypotheses, and a search for mechanism, can be built. Most importantly, this perspective will provide a more complete understanding of whether marine calcifiers have the physiological plasticity to compensate for the effects of ocean acidification and continue to build skeletons under future $\mathrm{CO}_{2}$ conditions. Microarray expression profiling has been used in numerous studies on non-model organisms to reveal patterns of physiological response to environmental factors (Gracey 2007) and this approach has revealed important transcriptional responses to environmental stressors in non-model marine organisms (Podrabsky \& Somero 2004, de la Vega et al. 2007, Kassahn et al. 2007, Kultz et al. 2007, Teranishi \& Stillman 2007, Place et al. 2008). In an ocean acidification scenario, one notable organismal function that would be perturbed is acid/base balance (Pörtner et al. 2005). Organismal studies have shown an effect of $\mathrm{CO}_{2}$ on acid/base balance in calcifiers such as sea urchins (Miles et al. 2007). Thus, the study of acid/base bal- ance in marine organisms is an example of how gene expression profiling might reveal genes that are changing, or steps in metabolic pathways that are being altered, in response to a changing abiotic environment. Finally, recent studies on coral larvae have identified genes that are involved in the cross-talk between the algal symbionts and the invertebrate host (de Boer et al. 2007). Such studies could be extended to assess the effects of ocean acidification on the algalcoral symbioses from a more global perspective, i.e. whether the association of coral with their Symbiodinium sp. symbionts will change as a function of different seawater chemistry.

\section{SUMMARY}

The application of genomics approaches to the question of the impact of ocean acidification will likely develop as fast as the resources become available. With the increase in the use of cross-species hybridizations (Buckley 2007), there is the opportunity to extend these resources without making gene chips for every species under study. Overall, gene expression profiling gives us a powerful tool to begin to understand how the physiology of marine calcifying organisms is likely to change in the face of a more acidic ocean. Targeted studies of individual species are significant in that each calcifier's response will vary and thus the ecosystemlevel impact will be transduced through the physiology of key species. Although gene expression is but one technique (there are other approaches in systems biology, e.g. proteomics or metabolomics), there is great potential to learn about the complexity of the compensatory responses in calcification and other metabolic pathways under ocean acidification conditions. Additionally, transcriptome profiling and its ability to reveal subtle, complex patterns will be a powerful approach to tease apart interacting stressors such as the synergistic effects of ocean acidification and warming, the 'double jeopardy' scenario within global climate change. Overall, the use of functional genomics will contribute to 2 important unknowns in the effort to forecast the effects of ocean acidification on marine ecosystems: (1) What are the basic organismal responses to the predicted levels of $\mathrm{CO}_{2}$ ? and (2) Will marine calcifying organisms have sufficient plasticity to build skeletons in a high- $\mathrm{CO}_{2}$ world?

Acknowledgments. The authors thank Dr. H. I. Browman and Dr. A. F. Vézina, for the invitation to contribute to this Theme Section on ocean acidification. In addition, we are indebted to Dr. S. P. Place (University of South Carolina) for the information presented in Table 1. Thanks, too, to Dr. M. A. Sewell (University of Auckland) for helpful comments that improved the manuscript. The authors acknowledge the US National 
Science Foundation for financial support during the course of this writing project (NSF grants OCE-0425107 and ANT0440799 to G.E.H.). This is contribution no. 263 from the Partnership for Interdisciplinary Studies of Coastal Oceans (PISCO) funded primarily by the Gordon and Betty Moore Foundation and the David and Lucile Packard Foundation.

\section{LITERATURE CITED}

Allemand D, Ferrier-Pages C, Furla P, Houlbreque F and others (2004) Biomineralisation in reef-building corals: from molecular mechanisms to environmental control. C R Palevol 3:453-467

Buckley BA (2007) Comparative environmental genomics in non-model species: using heterologous hybridization to DNA-based microarrays. J Exp Biol 210:1602-1606

Cohen AL, McConnaughey TA (2003) A geochemical perspective on coral mineralization. In: Dove PM, DeYoreo JJ, Weiner S (eds) Biomineralization. Rev Mineral Geochem 54:151-187

de Boer ML, Krupp DA, Weis VM (2007) Proteomic and transcriptional analyses of coral larvae newly engaged in symbiosis with dinoflagellates. Comp Biochem Physiol D 2:63-73

de la Vega E, Hall MR, Wilson KJ, Reverter A, Woods RG, Degnan BM (2007) Stress-induced gene expression profiling in the black tiger shrimp Penaeus monodon. Physiol Genomics 31:126-138

Desalvo MK, Voolstra CR, Sunagawa S, Schwarz JA and others (2008) Differential gene expression during thermal stress and bleaching in the Caribbean coral Montastraea faveolata. Mol Ecol 17:3952-3971

Doney SC, Fabry VJ, Feely RA, Kleypas JA (2009) Ocean acidification: the other $\mathrm{CO}_{2}$ problem. Annu Rev Mar Sci (in press) doi:10.1146/annurev.marine.010908.163834

Fabry VJ, Seibel BA, Feely RA, Orr JC (2008) Impacts of ocean acidification on marine fauna and ecosystem processes. ICES J Mar Sci 65:414-432

Forêt S, Kassahn K, Grasso L, Hayward D, Iguchi A, Ball E, Miller D (2007) Genomic and microarray approaches to coral reef conservation biology. Coral Reefs 26: 475-486

Fukuda I, Ooki S, Fujita T, Murayama E, Nagasawa H, Isa Y, Watanabe T (2003) Molecular cloning of a cDNA encoding a soluble protein in the coral exoskeleton. Biochem Biophys Res Commun 304:11-17

Gattuso JP, Allemand D, Frankignoulle M (1999) Photosynthesis and calcification at cellular, organismal and community levels in coral reefs: a review on interactions and control by carbonate chemistry. Am Zool 39:160-183

Gracey AY (2007) Interpreting physiological responses to environmental change through gene expression profiling. J Exp Biol 210:1584-1592

Guinotte JM, Fabry VJ (2008) Ocean acidification and its potential effects on marine ecosystems. Ann N Y Acad Sci 1134:320-342

- Hofmann GE, Burnaford JL, Fielman KT (2005) Genomicsfueled approaches to current challenges in marine ecology. Trends Ecol Evol 20:305-311

Jenny M, Chapman R, Mancia A, Chen Y and others (2007) A cDNA microarray for Crassostrea virginica and C. gigas. Mar Biotechnol 9:577-591

Kassahn KS, Caley MJ, Ward AC, Connolly AR, Stone G, Crozier RH (2007) Heterologous microarray experiments used to identify the early gene response to heat stress in a coral reef fish. Mol Ecol 16:1749-1763

Kleypas JA, Feely RA, Fabry VJ, Langdon C, Sabine CL, Rob- bins LL (2006) Impacts of ocean acidification on coral reefs and other marine calcifiers: a guide for future research. Report of a workshop held 18-20 April 2005, St. Petersburg, FL, sponsored by NSF, NOAA, and US Geological Survey Kultz D, Fiol D, Valkova N, Gomez-Jimenez S, Chan SY, Lee J (2007) Functional genomics and proteomics of the cellular osmotic stress response in 'non-model' organisms. J Exp Biol 210:1593-1601

Kurihara H, Shirayama Y (2004) Effects of increased atmospheric $\mathrm{CO}_{2}$ on sea urchin early development. Mar Ecol Prog Ser 274:161-169

Livingston BT, Killian CE, Wilt F, Cameron A and others (2006) A genome-wide analysis of biomineralization-related proteins in the sea urchin Strongylocentrotus purpuratus. Dev Biol 300:335-348

Lowenstam HA, Weiner S (1989) On biomineralization. Oxford University Press, New York

> Marshall AT, Clode PL, Russell R, Prince K, Stern R (2007) Electron and ion microprobe analysis of calcium distribution and transport in coral tissues. J Exp Biol 210: $2453-2463$

Mayfield AB, Hirst MB, Gates RD (2009) Gene expression normalization in a dual-compartment system: a real-time quantitative PCR protocol for symbiotic anthozoans. Mol Ecol Res (in press)

Miles H, Widdicombe S, Spicer JI, Hall-Spencer J (2007) Effects of anthropogenic seawater acidification on acidbase balance in the sea urchin Psammechinus miliaris. Mar Pollut Bull 54:89-96

Place S, O'Donnell MJ, Hofmann G (2008) Gene expression in the intertidal mussel Mytilus californianus: physiological response to environmental factors on a biogeographic scale. Mar Ecol Prog Ser 356:1-14

Podrabsky JE, Somero GN (2004) Changes in gene expression associated with acclimation to constant temperatures and fluctuating daily temperatures in an annual killifish Austrofundulus limnaeus. J Exp Biol 207:2237-2254

Pörtner HO, Langenbuch M, Michaelidis B (2005) Synergistic effects of temperature extremes, hypoxia, and increases in $\mathrm{CO}_{2}$ on marine animals: from earth history to global change. J Geophys Res 110,C09S10, doi: 10.1029/ 2004JC002561

Puverel S, Tambutté E, Zoccola D, Domart-Coulon I and others (2005) Antibodies against the organic matrix in scleractinians: a new tool to study coral biomineralization. Coral Reefs 24:149-156

Puverel S, Houlbreque F, Tambutté E, Zoccola D and others (2007) Evidence of low molecular weight components in the organic matrix of the reef building coral, Stylophora pistillata. Comp Biochem Physiol A 147:850-856

Quinn $\mathrm{P}$, Bowers RM, Zhang X, Wahlund TM, Fanelli MA, Olszova D, Read BA (2006) cDNA microarrays as a tool for identification of biomineralization proteins in the coccolithophorid Emiliania huxleyi (Haptophyta). Appl Environ Microbiol 72:5512-5526

Royal Society (2005) Ocean acidification due to increasing atmospheric carbon dioxide. Royal Society, London

Schwarz JA, Brokstein PB, Voolstra CR, Terry AY and others (2008) Coral life history and symbiosis: functional genomic resources for two reef building Caribbean corals, Acropora palmata and Monastraea faveolata. BMC Genomics 9:97

Sea Urchin Genome Sequencing Consortium (2006) The genome of the sea urchin Strongylocentrotus purpuratus. Science 314:941-952

Tambutté E, Allemand D, Zoccola D, Meibom A, Lotto S, Caminiti N, Tambutté S (2007) Observations of the tissue- 
skeleton interface in the scleractinian coral Stylophora pistillata. Coral Reefs 26:517-529

Tambutté S, Tambutté E, Zoccola D, Caminiti N and others (2007) Characterization and role of carbonic anhydrase in the calcification process of the azooxanthellate coral Tubastrea aurea. Mar Biol 151:71-83

Teranishi KS, Stillman JH (2007) A cDNA microarray analysis of the response to heat stress in hepatopancreas tissue of the porcelain crab Petrolisthes cinctipes. Comp Biochem Physiol D 2:53-62

Submitted: December 3, 2007; Accepted: October 15, 2008
Vera JC, Wheat CW, Fescemyer HW, Frilander MJ, Crawford DL, Hanski I, Marden JH (2008) Rapid transcriptome characterization for a nonmodel organism using 454 pyrosequencing. Mol Ecol 17:1636-1647

Wilt FH (2002) Biomineralization of the spicules of sea urchin embryos. Zool Sci 19:253-261

Zoccola D, Tambutté E, Senegas-Balas F, Michiels JF, Failla JP, Jaubert J, Allemand D (1999) Cloning of a calcium channel $\alpha 1$ subunit from the reef-building coral, Stylophora pistillata. Gene 227:157-167

Proofs received from author(s): December 9, 2008 